attendants in sleeping cars. The same legislation includes those who work in the health service, in the pharmaceutical industry, and-shades of the past-as glass-blowers in glass-works if blow tubes are used.

An obsession with food likewise lingers. In Tasmania no person suffering from a venereal disease may carry, deliver, manufacture, prepare, or otherwise handle any food intended for human consumption. Likewise in Poland no person with infectious syphilis may pursue an occupation which involved the production, storage, or distribution of food stuffs-even attendants in refrigerated railway wagons, and those concerned with the production, harvesting, and storage of farm products, including all who work in agricultural cooperatives, although paradoxically those engaged on their own farms are excluded.

In all fields, particularly venereal disease control, legislation itself is not enough. It is the necessity and possibility of enforcement which are all-important. Some countries (e.g., Nigeria-not included in the survey) have most extensive legislation, but it is either not enforceable or is unrealistic or outdated in the present era of rapidly-acting antibiotics.

On the vexed question of notification, non-nominal notification is required, for example, in the Federal Republic of Germany, France, Italy, the German Democratic Republic, and Sweden. In the sole reference to the United Kingdom it is stated, "Nevertheless it remains true that venereal disease legislation in a number of countries, such as the United Kingdom, New Zealand, and the Netherlands, does not require the notification of these diseases.' Such considerations taken solely in the context of legislation could be interpreted by the uninitiated reader as indicating that statistics and contact tracing in this country are likely to be deficient, whereas the comprehensiveness of the statistics, at least, are without parallel.

Within the declared scope of this survey its compilers are to be congratulated on a difficult task well done and all venereologists should possess a copy.

\section{R. R. Willcox}

The V.D. Epidemic. By Louis Lasagna. 1975. Pp. 160, figs, index. Temple University Press, Philadelphia (\$6-95)

Dr. Lasagna presents the facts about America's current syphilis and gonorrhoea problems in racy style. The presentation seems calculated to leave one breathlessand sometimes does. The dust cover sets the pace with the letters 'V.D.' coming at one, threateningly, and matching the heading of the first chapter-'The Monster Revives.'

But soon one settles to appreciate the sound, careful, and well ordered nature of the book. No aspect of the two diseases is neglected-historical, clinical, laboratory, research, epidemiological, educational, or social. Everything is here for the enquiring layman, together with much that will brighten formal lectures to students and nurses. Those young venereologists and health educators aspiring to communicate well on the subject will find much that is worthy of imitation. There is a list of 87 well selected references and many others are quoted or skillfully worked, in precis, into the narrative. In a book aimed at the American layman, the great majority of the sources used in the exposition are-and rightly sofrom the literature of the U.S.A. The photographs are of modest quality and the glossary useful. There is a list of books for further reading.

The author sees clearly enough the contrast between the high and well maintained quality of research and the inadequacy of sustained control measures in America. He bemoans also the absence of a top level socio-political lobby and sees little hope of improvement with the current gloomy economic scene (p. 11).

The historical aspects of the two diseases are accurate enough and brief. The chapter on symptoms, sources,, and consequences is thorough and concise, and strikes a good balance in terms of the number of pages devoted to each condition. (Sexually transmitted diseases other than syphilis and gonorrhoea are dealt with in less than three pages.) One can of course quibble about detail. It is the endocervix rather than the cervix which is infected in gonorrhoea and many would object to the implication that gonorrhoea causes a vaginitis (p. 35). Laboratory aspects are presented in a way that surmounts the difficulties inherent in explaining their technicalities. 'Heavy Metals and the Tuskegee Scandal' as a chapter gives an insight into further history, both ancient and modern. It is followed by 'The Advent of Effective Therapy', which is the best chapter in the book. It covers, besides much else, preventive and specific measures as well as the case for and against epidemiological treatment. Under the heading of 'The Gift That Keeps on Giving', the author deals with the pitfalls, problems, and polemics of contact tracing. We find him an ardent advocate. He sees contact tracing as the outstanding element in a holistic approach to control.

On feels that in his heart Dr. Lasagna believes that syphilis and gonorrhoea are too important, too distressing, dangerous, and costly to be left to private physicians. Alas, he fails to say so because he fails to realise that the Swedish and British approaches-both are mentioned with misgivings - really do have personal, medical, epidemiological, social, and economic advantages (p. 121). If only he had seen the light, and followed it through logically, this would have been the best book of its kind to emerge from the U.S.A. - and he could have been forgiven for the irritating habit of using the word 'bugs'.

\section{R. S. Morton}

